\title{
Electrodeposited Gold Composites
}

\author{
PARTICLE-HARDENED GOLD FOR ENHANCED WEAR \\ RESISTANCE IN SLIDING CONTACT APPLICATIONS
}

\author{
Clive Larson
}

Fulmer Research Institute, Stoke Poges, England

\begin{abstract}
Co-deposited refractory carbide particles in gold electroplates have been shown to enhance the hardness, the tensile strength and the sliding wear resistance of the gold. The low electrical contact resistance of gold is not significantly impaired by the presence of the carbide particles.
\end{abstract}

Because of its negligible tendency to tarnish and its high conductivity and low contact resistance, gold is extensively used in the electronics industry in the electrodeposited form as a contact surface. For most sliding contact applications pure gold is too soft, with an inherent tendency to cold-weld on mating, thus causing tearing and rupture of the coating. It is known that better wear properties may be obtained by low alloy hardening of the gold plate for example with 0.1 to 0.5 per cent of cobalt or nickel. These improvements can, however, have a deleterious effect on tarnish resistance, contact resistance and deposit conductivity.

The work reported in this paper, carried out on behalf of the South African Chamber of Mines, was an attempt to achieve improved sliding wear resistance of gold electrodeposits while maintaining tarnish resistance and electrical properties. This has been achieved by the use of composite gold electroplates in which conducting, tarnish resistant refractory carbide particles are uniformly dispersed in a pure gold matrix.

The use of gold-based composites for increased strength and creep resistance has been intermittently studied in recent years. Sautter $(1,2)$ found that codeposition of alumina particles with gold electrodeposits considerably improved the creep resistance of the gold. Gimpl and Fuschillo $(3,4)$ have produced gold composites with alumina and thoria by chemically precipitating gold metal onto the oxide particles and then pressing and sintering the composite powder. Recrystallisation and grain growth of the dispersion hardened gold were retarded and the mechanical properties at elevated temperatures were reported to be particularly enhanced.

A similarly prepared alloy, but using titania as the dispersed phase, has been studied by Poniatowski and Clasing (5) who claim improvements over the gold- alumina and gold-thoria composites. Little improvement in ambient temperature hardness has been reported for such composites, which may preclude their use in sliding wear applications.

A co-deposited gold-tungsten carbide composite has been reported $(6)$ to improve the welding and metal transfer characteristics of reed switch and speciality relay applications, but no details of process conditions or deposit compositions have been given.

\section{Experimental}

The composite electrodeposits were produced by adding a ball-milled slurry of approximately $1 \mu \mathrm{m}$ average diameter titanium or tungsten carbide powder in a small volume of gold electrolyte to the rest of the electrolyte. This was stirred well to obtain a uniform dispersion of powder, and plating was carried out in the recommended current density and temperature ranges of the plating bath.

Two types of gold solution were used:

(1) Acid gold complex cyanide $\mathrm{pH} 5.5$, current density 0.5 to $1.0 \mathrm{~A} / \mathrm{dm}^{2}$, temperature $60^{\circ} \mathrm{C}$, gold concentration $10 \mathrm{~g} / 1$.

(2) Alkaline gold complex sulphite $\mathrm{pH} 9.5$, current density 0.3 to $0.6 \mathrm{~A} / \mathrm{dm}^{2}$, temperature $60^{\circ} \mathrm{C}$, gold concentration $10 \mathrm{~g} / 1$.

The amounts of carbide co-deposited with gold under different operating conditions and bath powder contents were chemically analysed for the two baths and confirmed by optical microscopy using metallographically polished transverse cross-sections. Microhardness data were obtained on polished crosssections of thick $(25 \mu \mathrm{m})$ composite deposits using a Vickers instrument with a $10 \mathrm{~g}$ load. At least 10 measurements were made on each specimen.

Composite deposits of different carbide contents were stripped from the copper substrates by immersion in cold dilute nitric acid and annealed in air at 


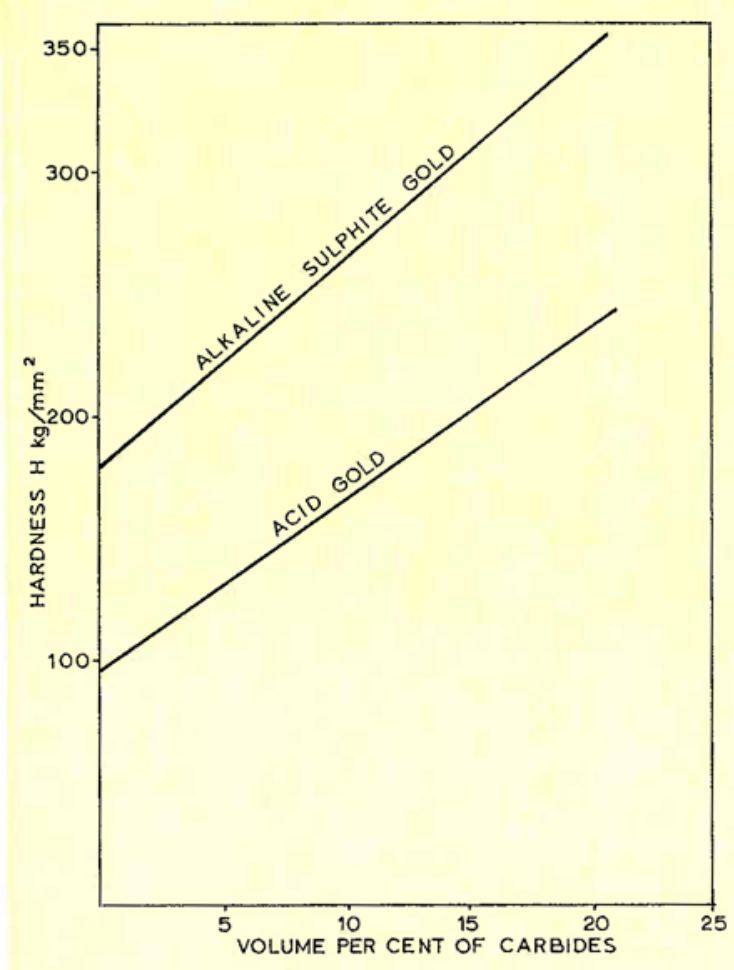

Fig. 1 Effect of co-deposited refractory carbides on the hardnesses of two different gold electroplates

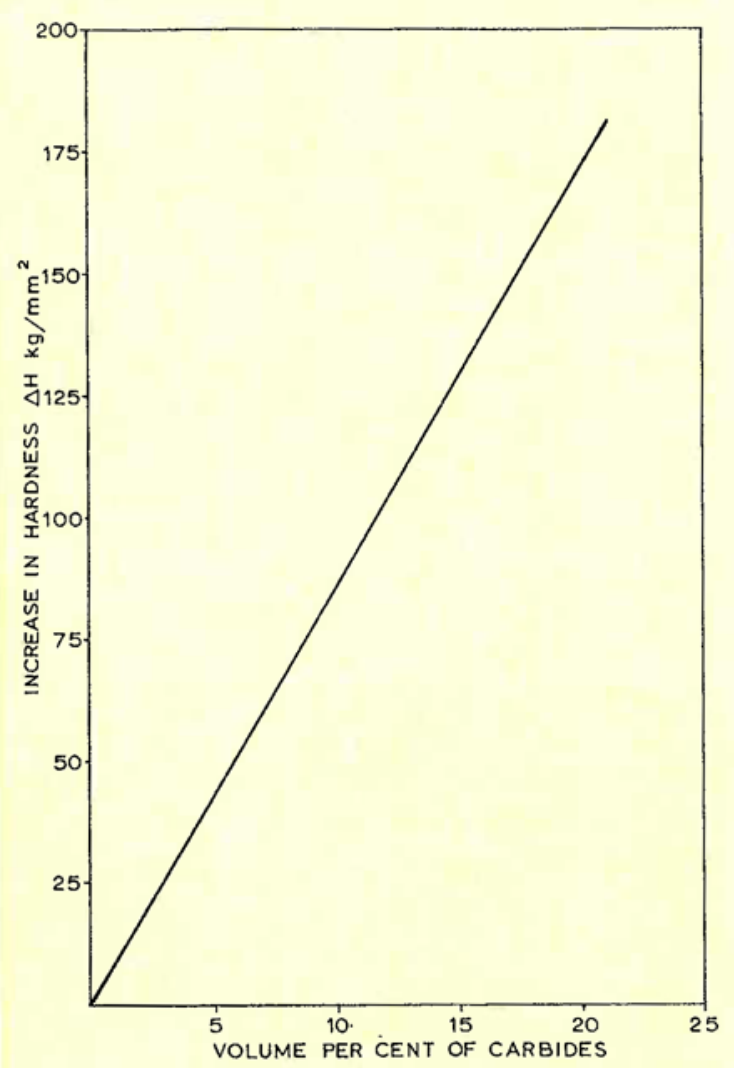

Fig. 2 The hardening effect of refractory carbides in gold deposits as a function of the volume percentage of the carbides in the deposits
$200,400,600$ and $800^{\circ} \mathrm{C}$ for 1 hour. The foils were then mounted and polished for further microhardness determination to assess the effect of incorporated carbides on the annealing characteristics of the gold.

Tensile tests were carried out at ambient and elevated temperatures $\left(100,200\right.$ and $\left.300^{\circ} \mathrm{C}\right)$ in air in an Instron T T-DM floor model tensile machine at a speed of $0.02 \mathrm{~cm} / \mathrm{min}$. The specimens were formed by plating the gold-carbide composite deposits on to copper foil standard tensile shapes of nominal gauge width $0.635 \mathrm{~cm}$ and dissolving the $2.54 \mathrm{~cm}$ gauge length copper away in nitric acid.

The sliding wear and contact resistance data have been obtained concurrently during wear testing of the composite coatings in a rider-flat instrument similar to that used by Antler (7) and others. The coatings were applied to flat, copper plated, aluminium discs which revolved at $8 \mathrm{~cm} / \mathrm{sec}$ under a rigid hemispherical loop of a hard alloy gold wire (JM625) at $45 \mathrm{~g}$ loading. After $10^{6} \mathrm{~cm}$ sliding length the wear tracks on the gold deposits and the wear on the rider were assessed by optical and stercomicroscopy, and the composite volume wear estimated.

The static contact resistances of the composite golds against the JM625 wire were measured at intervals during the test.

\section{Results and Discussion}

The main factor affecting the volume fraction of carbide co-deposited with gold in a given system was found to be the concentration of powder in the electrolyte, the relationship being approximately parabolic:

$$
\mathrm{V}_{\mathrm{p}}{ }^{2} \propto \mathrm{C}
$$

$\mathrm{V}_{\mathrm{p}} \equiv$ volume per cent of carbide co-deposited with gold.

$\mathrm{C} \equiv$ concentration in the gold bath in $\mathrm{g} / \mathrm{l}$.

The amount co-deposited also depended on the system under test, for a given set of conditions:

$\mathrm{V}_{\mathrm{p}}$ (Alkaline sulphite-TiC) $\sim \mathrm{V}_{\mathrm{p}}$ (Acid gold cyanide - WC) $>V_{p}$ (Alkaline sulphite- $W C$ ) $>V_{p}$ (Acid gold cyanide-TiC).

Depending on the operating conditions, codeposited carbide contents of up to 20 per cent by volume can be achieved, the electroformed foils being sufficiently ductile to withstand considerable bending before fracture.

The as-deposited hardness of gold-carbide composites increases with the volume fraction of carbide present and with the hardness of the gold matrix. Within the experimental range of carbide contents the composite hardness is virtually independent of the type of carbide used. If only increase in hardness over matrix gold $\left(\Delta \mathrm{H} \mathrm{kg} / \mathrm{mm}^{2}\right)$, or particle hardening effect, is considered, all data lie reasonably on the same line. Figures 1 and 2 show these relationships. 
Figure 3 shows the effect of codeposited carbide on the thermal softening of gold plate. Data for gold foils containing 12 and 17 volume per cent tungsten carbide and pure gold from an acid gold complex cyanide bath are given in microhardness-annealing temperature graphs. Both composite deposits show considerably enhanced hardness over pure gold-approximately in the ratio of the carbide content-up to about $300^{\circ} \mathrm{C}$ annealing temperature. All three deposits softened when annealed above this temperature, the dilute dispersion composite becoming as soft as gold at approximately $600^{\circ} \mathrm{C}$.

The 17 per cent gold-carbide composite, although softening when annealed at $300^{\circ} \mathrm{C}$, remained about $35 \mathrm{~kg} / \mathrm{mm}^{2}$ harder than pure gold for all annealing temperatures above $300^{\circ} \mathrm{C}$, being 1.5 times as hard after annealing at $800^{\circ} \mathrm{C}$.

The tensile test data for pure gold and gold- 10 per cent titanium carbide deposits shown in the table indicate the presence of particle strengthening in the composite at temperatures of up to $250^{\circ} \mathrm{C}$. Useful ductility was retained in many composites.

In continuous sliding contact with a hard gold alloy wire (JM625) the wear resistance (taken as the inverse of the wear track volume) of the composites increased with the amount of carbide present, and the deposit hardness, a 15 per cent carbide content giving a 500 per cent improvement in wear resistance over pure gold plate. Within the experimental scatter all four test systems (acid cyanide and alkaline sulphite

\section{Effect of Co-deposited Refractory Carbide Particles on the Tensile Strength of Gold Electrodeposits}

\begin{tabular}{c|c|c}
\hline Specimen & $\begin{array}{c}\text { Test } \\
\text { Temperature }\end{array}{ }^{\circ} \mathrm{C}$ & $\begin{array}{c}\text { UTS } \\
\mathrm{N} / \mathrm{m}^{2} \times 10^{-7}\end{array}$ \\
\hline $\mathrm{Au}$ & 20 & 22.3 \\
$\mathrm{Au}$ & 100 & 15.0 \\
$\mathrm{Au}$ & 200 & $\simeq 9^{*}$ \\
$\mathrm{Au}$ & 300 & 5.7 \\
$\mathrm{Au}-\mathrm{TiC}$ & 20 & 28.9 \\
$\mathrm{Au}-\mathrm{TiC}$ & 100 & 31.2 \\
$\mathrm{Au}-\mathrm{TiC}$ & 200 & 17.8 \\
$\mathrm{Au}-\mathrm{TiC}$ & 300 & 0.9
\end{tabular}

The Au-TiC specimens contained 10 volume per cent of $1 \mu \mathrm{m}$ TiC particles

* Interpolated value golds with titanium and tungsten carbides) approximately fit the same relationship, as shown in Figure 4.

The contact resistances of the test deposits versus JM625 alloy during $10^{6} \mathrm{~cm}$ sliding contact showed that, on average, gold-refractory carbide composites had only marginally higher contact resistances than pure gold surfaces $(1.08 \mathrm{mohm}$ compared to 0.78 mohm). The corresponding values for electroplated palladium and rhodium are 7.09 and $2.61 \mathrm{mohm}$ respectively.

The relationships observed between composition of gold-carbide deposits and composition of electrolyte, and between mechanical properties and composition of the deposits, are quite consistent with the reported data for many other systems, e.g., $\mathrm{Ni}-\mathrm{Al}_{2} \mathrm{O}_{3}$ $(8,9,10), \mathrm{Ni}^{-\mathrm{TiO}_{2}}(9,10,11,12), \mathrm{Ni}-\mathrm{SiC}(12), \mathrm{Fe}-\mathrm{Al}_{2} \mathrm{O}_{3}$ (13), some of which have found major industrial usage. Examples of these are Ni-SiC for hard, wear-resistant rotor housing faces in Wankel engines, and $\mathrm{Ni}-\mathrm{SiO}_{2}$ as a base plate for microdiscontinuous bright chromium plating.

Because of the size range of the carbide particles used in this work and the observed mechanical properties it is not thought likely that true dispersion hardening through restriction of dislocation movement through the metal matrix is the only cause of the observed improvements in hardness, tensile strength and wear resistance in the gold-carbide 


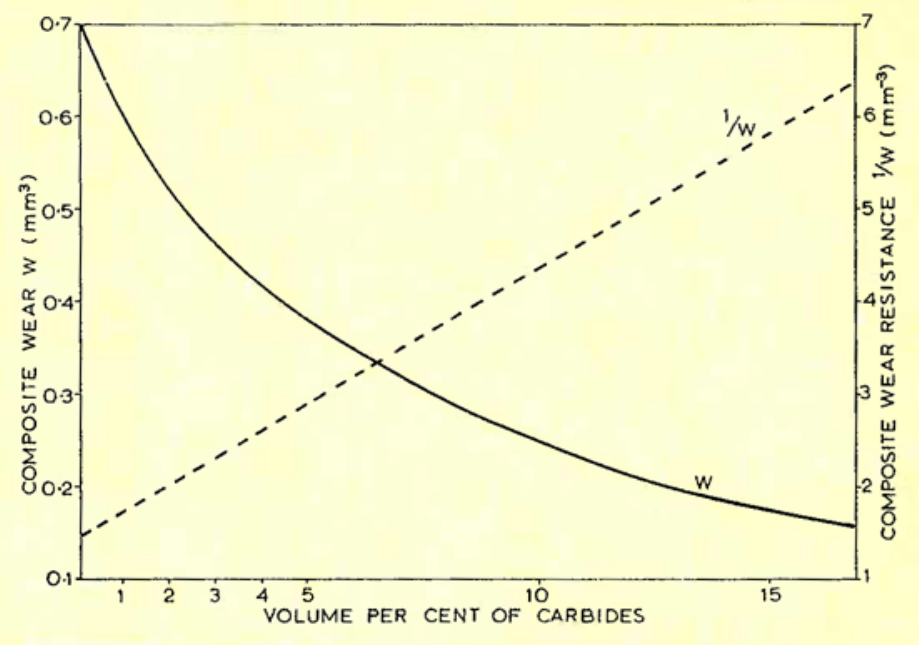

Fig. 4 Dependence of composite wear and wear resistance on the amount of carbide present in the gold deposit. All four systems investigated-acid cyanide and alkaline sulphite golds with titanium and tungsten carbides - gave approximately the same relationship

composites. It is probable that mechanical restraint of matrix deformation by the hard non-deformable particles plays an important role in strengthening.

\section{Conclusions}

Composite gold-refractory carbide coatings formed by electrodeposition have been found to have considerably enhanced hardness, strength, and rubbing wear characteristics compared to gold electroplate. Because the carbide particles are chemically inert the corrosion resistance and electrical contact resistance properties approach those of pure gold.

It is considered that such deposits could find extensive use in sliding contact applications in which exposure and tarnishing of substrate base metal through wear of the gold plate is a problem. Similar considerations may encourage the use of composite gold electroplates in decorative jewellery applications especially with the possibility of obtaining various attractive finishes by varying the size and volume of co-deposited particles.

\section{Acknowledgements}

The author would like to thank the Chamber of Mines of South Africa for its support of this work and for permission to publish this paper. Acknowledgement is also made to Mr. M. A. R. Baig, now with Precision Circuits Ltd., Hayes, England, for his contribution to the research.

\section{References}

1 F. K. Sautter, "Electrodeposition of Dispersion Strengthened $\mathrm{Au}-\mathrm{Al}_{2} \mathrm{O}_{3}$ Alloys", Watervliet Arsenal Tech. Rept., 1963 RR-6321

2 F. K. Sautter, Metall, 1964, 18, (6), 596

3 M. L. Gimpl and N. Fuschillo, Metal. Soc. Conf., "Oxide Dispersion Strengthening", 1966, 47, 719, Publ. by Gordon \& Breach

4 N. Fuschillo and M. L. Gimpl, F. Mater. Sci., 1970, 5, 1078

$5 \mathrm{M}$. Poniatowski and M. Clasing, Gold Bull., 1972, 5, (2), 34

6 H. R. Peiffer et al., Proc. 17th Ann. Nat. Relay Conf., 1969, 1

7 M. Antler, ASLE Trans., 1962, 5, 297

8 F. K. Sautter, F. Electrochem. Soc., 1963, 110, 557

9 F. J. Dunkerley et al., Metal. Soc. Conf. "Oxide Dispersion Strengthening", 1966, 47, 695

10 V. P. Greco and W. Baldauf, Plating, 1968, 55, 250

11 M. Pushpavanam et al., Metal Finish, 1974, 72, (10), 46

12 N. Guglielmi, f. Electrochem. Soc., 1972, 119, 1009

13 D. S. R. Brown and K. V. Gow, Plating, 1972, 59, 437

\section{Bibliographic Reviews on the Electrodeposition of Gold Alloys}

While the extensive literature on gold plating is readily available, the subject of the deposition of gold alloys-in which so much interest is now being taken-is not so well documented. Published information in this field has now been assembled by $\mathrm{Dr}$ W. S. Rapson of the Chamber of Mines of South Africa Research Organisation and has been incorporated in a series of bibliographical reviews as follows:

Part I Electrodeposition of gold with copper and silver

Part II Electrodeposition of gold with zinc, cadmium, gallium, indium, thallium, tin, lead, antimony and bismuth

Part III Electrodeposition of gold with cobalt, nickel and iron

Part IV Electrodeposition of gold with the platinum group metals, and with chromium, molybdenum, uranium, tungsten and manganese.

Copies of these reviews may be obtained by writing to the Research Organisation, Chamber of Mines of South Africa, P.O. Box 809, Johannesburg, South Africa. 